\title{
Fasting affects the surface and diving metabolic rates of Steller sea lions Eumetopias jubatus
}

\author{
C. Svärd ${ }^{1}$, A. Fahlman ${ }^{2,3, *}$, D. A. S. Rosen ${ }^{2}$, R. Joy ${ }^{2}$, A.W. Trites ${ }^{2}$ \\ ${ }^{1}$ Division of Zoology, Department of Physics, Chemistry and Biology (IFM), Linkoping University, 58283 Linköping, Sweden \\ ${ }^{2}$ Marine Mammal Research Unit, Fisheries Centre, Room 247, AERL, University of British Columbia, Vancouver, \\ British Columbia, V6T 1Z4, Canada \\ ${ }^{3}$ Present address: Department of Biology, Woods Hole Oceanographic Institution, 266 Woods Hole Road, Woods Hole, \\ Massachusetts 02649, USA
}

\begin{abstract}
Changes in metabolic rates were measured in 3 captive female Steller sea lions Eumetopias jubatus that experienced fasts during summer and winter. We measured metabolic rates (via $\mathrm{O}_{2}$ consumption) before $\left(\mathrm{MR}_{\mathrm{s}}\right.$, surface) and after (DMR, dive + surface interval) the sea lions dove to 10-50 m depths. Measurements were obtained prior to and immediately after 9 to $10 \mathrm{~d}$ fasts, and during a $14 \mathrm{~d}$ recovery period. The sea lions lost significantly more body mass $\left(M_{\mathrm{b}}\right)$ during the winter fast $(10.6 \%)$, compared with the summer $(9.5 \%)$. Mass-corrected dive metabolic rate $\left({ }_{\mathrm{c}} \mathrm{DMR}=\mathrm{DMR} \times\right.$ $M_{\mathrm{b}}{ }^{-0.714}$ ) was not affected by dive depth or duration, but increased significantly following the winter fasts $(13.5 \pm 8.1 \%)$, but did not change during summer $(-1.1 \pm 3.2 \%)$. However, mass-corrected surface metabolic rate $\left({ }_{\mathrm{c}} \mathrm{MR}_{\mathrm{s}}\right)$ decreased significantly after both the summer $(-16.4 \pm 4.7 \%)$ and winter $(-8.0 \pm$ $9.0 \%$ ) fasts. Consequently, the ratio between ${ }_{C} D M R$ and ${ }_{C} M R_{s}$ was significantly higher in winter, suggestive of an increased thermal challenge and convective heat loss while diving. Increased ${ }_{\mathrm{C}} \mathrm{MR} \mathrm{s}_{\mathrm{s}}$ following the fast indicated that digestion began during foraging and was not deferred, implying that access to ingested energy was of higher priority than optimizing diving ability. ${ }_{\mathrm{C}} \mathrm{DMR}$ was elevated throughout the recovery period, independent of season, resulting in a $12 \%$ increase in foraging cost in winter and a $3 \%$ increase in summer. Our data suggest that Steller sea lions are more sensitive to changes in body condition due to food shortages in the winter compared with the summer.
\end{abstract}

KEY WORDS: Diving physiology $\cdot$ Body condition $\cdot$ Digestion

\section{INTRODUCTION}

The rate at which marine mammals consume $\mathrm{O}_{2}$ ultimately determines their aerobic dive duration and the efficiency with which they forage (Kooyman \& Ponganis 1998, Costa \& Sinervo 2004). Marine mammals have developed different physiological and behavioural strategies to conserve $\mathrm{O}_{2}$ to maximize diving time and foraging efficiency. For example, seals may defer digestion until the end of a foraging bout (Sparling et al. 2007) and increase efficiency of diving by interspersing periods of active swimming with long episodes of passive gliding (Williams et al. 2000). Diving seals can also become hypothermic and suspend shivering, which reduces metabolic rate and the $\mathrm{O}_{2}$ consumption rate (Kvadsheim et al. 2005).

Diving efficiency and optimal use of $\mathrm{O}_{2}$ may be negatively affected by substantial loss of insulative fat stores associated with reduced food intake (Webb et al. 1998, Watanabe et al. 2006). On the other hand, fasting-induced physiological changes include a reduction in metabolism as a means of reducing use of internal energy sources (Guppy \& Withers 1999). While fasting, subcutaneous fat is used as a nutritional resource and metabolic depression can extend the time these resources will last (Castellini \& Rea 1992). Most pinnipeds experience natural periods of fasting and respond with metabolic depression (Markussen \& 
Ryg 1992, Rea \& Costa 1992). This has been documented in fasted and food-restricted Steller sea lions Eumetopias jubatus (Shreber, 1776) on land (Rosen \& Trites 2002, Jeanniard du Dot et al. 2008). In most vertebrates, fasting-induced hypometabolism is the result of down-regulation of body functions such as protein synthesis, and thermoregulation to limit tissue catabolism (Øritsland 1990, Guppy et al. 1994). Consequently, hypometabolism that is fasting-induced may also increase the aerobic dive duration for marine mammals. Reduced insulative fat stores, on the other hand, may significantly increase heat loss and metabolic rate through increased thermoregulatory costs, thereby reducing aerobic dive duration.

Understanding how natural or unpredicted periods of fasting affect the metabolic cost of foraging is needed to predict the consequences of food shortages on the energy budget and foraging strategies of marine mammals (Williams et al. 2007). The aims of this study were: (1) to measure the metabolic rates of foraging Steller sea lions experiencing reduced food intake (i.e. acute fasting) to determine how fasting might affect the foraging costs of marine mammals, (2) to observe how quickly reductions in metabolic rates could be reversed when a fasted animal regained access to food, and (3) to investigate how fastinginduced changes in foraging costs vary with season to identify whether there are particular times of the year when Steller sea lions are more vulnerable to alterations in prey availability. Such information can be incorporated into future bioenergetic models to estimate total energy budgets and food requirements of wild Steller sea lions, and may help with population and fisheries management.

\section{MATERIALS AND METHODS}

Animals. All experiments were conducted under permits from Animal Care Committees of the University of British Columbia (UBC) and the Vancouver Aquarium, Canada. Experimental trials were conducted between May and November 2007. Three female Steller Sea lions were used in all trials; 2 sea lions were 9 years old (F97HA and F97SI) and the third was 6 years old (F00BO). The animals were housed and trained since pups at the Vancouver Aquarium and transferred to the UBC Open Water Research Station located in a coastal inlet in British Columbia in 2003 where the study took place. The animals were housed in a floating net pen $(3.6 \times 3.6 \times 6.1 \mathrm{~m})$ suspended in seawater with a haulout space.

The animals freely chose to cooperate and were never restrained or confined during the experimental trials. During each trial, the sea lion wore a body har- ness with an attached VHF transmitter and depth data logger (Sensus ReefNet Ultra U-05272). The VHF transmitter allowed the sea lion to be tracked in case the animal left the trial area. Body mass $\left(M_{\mathrm{b}}, \mathrm{kg}\right)$ was measured daily by having the animals hold position on a platform scale $( \pm 0.5 \mathrm{~kg}) . M_{\mathrm{b}}$ was measured before each trial and opportunistically during fasting (depending on animal cooperation).

Experimental conditions. The experiment consisted of three 9 to $10 \mathrm{~d}$ fasting sessions (Fast 1, 2, and 3). Fasts 1 and 2 were both conducted in the summer (3 May to 3 July 2007) and Fast 3 in the winter (22 October to 13 November 2007). Each fasting session consisted of a series of pre-fast diving trials followed by a fasting period and a subsequent 2 wk recovery period during which 5 post-fast dive trials were conducted at pre-determined intervals (Table 1). All trials were performed in the morning, at least $16 \mathrm{~h}$ and up to $216 \mathrm{~h}$ postprandial. To ensure that the sea lions were not naïve to the required dive parameters during a trial, each animal was trained at each depth for 5 to $7 \mathrm{~d}$ prior to collecting any data (see 'Trial procedure' for details of experimental setup).

Fasts 1 and 3 included dives to a maximum depth of either $30 \mathrm{~m}$ (F97SI) or $50 \mathrm{~m}$ (F97HA and F00BO), depending on the willingness of the individual sea lion (Table 2). During Fast 1, F97HA and F00BO would not dive to $50 \mathrm{~m}$ for the Post 1 and Post 2 trials. We therefore reduced the dive depth to between 20 to $40 \mathrm{~m}$ to collect post-fasting data. Fast 2 utilized only shallow dives to $10 \mathrm{~m}$ for all 3 animals. We evaluated how dive depth affected the metabolic rate of a dive event (DMR, dive + surface interval) by comparing the results of Fasts 1 and 2, and assessed seasonal changes by comparing Fasts 1-2 with Fast 3.

The sea lions' normal diet consisted of previously frozen herring (Clupea pallasii) and small quantities of squid, supplemented with vitamins. On the first day of fasting, the animals were fed $30 \%$ of their normal base amount in the morning, and were thereafter fasted for

Table 1. Eumetopias jubatus. Diving trial schedule for $3 \mathrm{fe}-$ male Steller sea lions during the recovery period after a 9 to $10 \mathrm{~d}$ fast. Pre-fast trials were control trials and were conducted before the onset of fasting. All days are relative to the last $\mathrm{d}$ of fast (Post 1), represented by Day 0

\begin{tabular}{|cc|}
\hline Trial & Days since end of fast \\
\hline Pre-fast & -11 to -24 \\
Fast & -9 to -10 \\
Post 1 & 0 \\
Post 2 & 1 to 2 \\
Post 3 & 4 to 5 \\
Post 4 & 7 to 8 \\
Post 5 & 12 to 13 \\
\hline
\end{tabular}


Table 2. Eumetopias jubatus. Dive depths (m) for 3 female Steller sea lions (F00BO, F97SI and F97HA) during 3 fasting sessions; summer (Fast 1, 2) and winter (Fast 3). nd: no data. Parentheses: no. of dives

\begin{tabular}{|llcccc|}
\hline Fast & Animal & Pre-fast & Post 1 & Post 2 & Post 3-5 \\
\hline 1 & F00BO & $50(7)$ & $30(8)$ & $50(4)$ & $50(4)$ \\
& F97SI & $30(6)$ & $30(6)$ & $30(5)$ & $30(4-5)$ \\
& F97HA & $50(6)$ & $20-40(6)$ & $30-50(4)$ & $50(4)$ \\
2 & F00BO & $10(6)$ & $10(6)$ & $10(3)$ & - \\
& F97SI & $10(6)$ & $10(7)$ & $10(4)$ & $10(4)$ \\
& F97HA & $10(6)$ & $10(6)$ & $10(4)$ & $10(5)$ \\
3 & F00BO & $50(6)$ & $50(7)$ & $50(4)$ & $50(4)$ \\
& F97SI & $30(6)$ & $30(6)$ & $30(4)$ & $30(4)$ \\
& F97HA & $50(6)$ & $50(6)$ & $50(4)$ & $50(4)$ \\
\hline
\end{tabular}

9 to $10 \mathrm{~d}$. The fasting period was designed to result in a total mass loss $\sim 10 \%$ of the initial $M_{\mathrm{b}}$, but not exceeding $15 \%$ (as per Animal Care protocols). During Fast 1, one sea lion (F97HA) would not dive during the Post 1 trial. She was therefore fasted for one more day, resulting in a total fasting period of $10 \mathrm{~d}$. During preparation for trials, transportation to the trial area, and during the Post 1 trial attempt, she received $\sim 7 \%$ of her normal daily food intake $(\sim 0.5 \mathrm{~kg})$. A minimal amount of food $(<100 \mathrm{~g})$ was given to the animals before each trial to facilitate separation from other animals in the pen area. Separate experiments not reported in this study were conducted to ensure that this amount of food did not affect the metabolic rate.

Average daily mass of the food intake (i.e. food base) was predetermined by the trainers and differed between animals depending on individual and seasonal $M_{\mathrm{b}}$. The sea lions received a significantly higher food base in the winter compared with the summer, both for the pre-fast period $(16.2 \pm 4.4 \%$; $p=0.0002$, average of the last $5 \mathrm{~d}$ prior to fasting) and the recovery period $(12.1 \pm 7.2 \% ; \mathrm{p}=0.0103$, avg. of the first $5 \mathrm{~d}$ after fasting). Mass-specific gross energy intake during the pre-fast period ranged from 215 to $474 \mathrm{~kJ} \mathrm{~kg}^{-1} \mathrm{~d}^{-1}$ in the summer (Fasts 1 and 2) and between 296 to $505 \mathrm{~kJ} \mathrm{~kg}^{-1} \mathrm{~d}^{-1}$ in the winter (Fast 3). During recovery, the aim was to increase $M_{\mathrm{b}}$ to pre-fast levels by the end of the $14 \mathrm{~d}$ period. Therefore, seasonal variation in mass-specific gross intake was also observed during the recovery period and ranged between 222 to $512 \mathrm{~kJ}$ $\mathrm{kg}^{-1} \mathrm{~d}^{-1}$ in the summer and from 356 to $566 \mathrm{~kJ} \mathrm{~kg}^{-1} \mathrm{~d}^{-1}$ in the winter. The higher food base in the winter was given to minimize differences in pre-fast weights between fasting sessions and to ensure that each sea lion had recovered and returned to the same pre-fast $M_{\mathrm{b}}$ before each fasting session. This increase in food base requirements during winter was comparable with previous studies $(18.7 \pm 3.6 \%$ increase in the winter $)$ (Jeanniard du Dot et al. 2008). The amount of food given during each trial varied on a daily basis, with sea lions receiving more food during trial days to secure animal motivation. Two sea lions showed signs of stomach discomfort during the recovery period of Fast 2 (F00BO from Post 2, F97HA from Post 4) and these animals were excluded from the study for the remainder of this recovery phase.

The trial area for Fast 1 and Fast 3 was situated in a fjord located $\sim 7 \mathrm{~km}$ from the location of the research station. The water depth at this location enabled dives up to $50 \mathrm{~m}$. The trial area for Fast 2 was near the research station, allowing dives up to $10 \mathrm{~m}$. The sea lions were transported to the trial area (Fast 1 and 3 ) by a specially designed $22 \mathrm{ft}(6.70 \mathrm{~m})$ transport boat. Another $22 \mathrm{ft}(6.70 \mathrm{~m})$ research boat carried the research equipment and towed a floating barge (containing the respirometry dome) to the trial area.

Experimental set up and variables measured. Variables are defined in (Table 3). Metabolic rates (MR) were estimated using flow-through respirometry to measure the $\mathrm{O}_{2}$ consumption rate $\left(\dot{V}_{\mathrm{O}_{2}} ; \mathrm{l} \mathrm{O}_{2} \mathrm{~min}^{-1}\right)$. The floating experimental barge had a rectangular hole into which a cage $(152 \times 152 \times 250 \mathrm{~cm})$ was placed. The cage extended into the water and was equipped with a submerged opening at the bottom and was manually closed to keep the animal in the cage after entering. It also had an open top into which a floating transparent Plexiglas respirometry dome (100 l internal volume) was placed where the animal could breathe.

A mass flow meter (Flow Kit Model 500H, Sable System Int.) pulled air through the dome at a flow rate of $4751 \mathrm{~min}^{-1}$. The mass flow meter automatically corrected flow rate to standard temperature and pressure (STP) despite variation in temperature and barometric pressure. The $\mathrm{O}_{2}$ and the $\mathrm{CO}_{2}$ levels in the expired air were determined by extracting a subsample of the air passing through a canister of anhydrous $\mathrm{CaSO}_{4}$ (W. A. Hammond Drierite) to a paramagnetic $\mathrm{O}_{2}\left(\mathrm{FC}-1 \mathrm{~B} \mathrm{O}_{2}\right.$, Sable Systems Int.) and an infrared $\mathrm{CO}_{2}$ analyzer (CA1B, Sable Systems Int.). Data were sampled at $2 \mathrm{~Hz}$ and

Table 3. Eumetopias jubatus. List of symbols and abbreviations

\begin{tabular}{|c|c|}
\hline Variable & Definition \\
\hline $\mathrm{d}_{\mathrm{f}}(\min )$ & $\begin{array}{l}\text { foraging time (excludes } \\
\text { ascent and descent time) }\end{array}$ \\
\hline $\mathrm{d}_{\mathrm{t}}(\min )$ & total dive time \\
\hline $\operatorname{DMR}\left(\mathrm{l} \mathrm{O}_{2} \mathrm{~min}^{-1}\right)$ & diving metabolic rate \\
\hline${ }_{\mathrm{c}} \mathrm{DMR}\left(\mathrm{ml} \mathrm{O}_{2} \mathrm{~min}^{-1} \mathrm{~kg}^{-0.714}\right)$ & $\begin{array}{l}\text { mass-corrected diving } \\
\text { metabolic rate }\end{array}$ \\
\hline$M_{\mathrm{b}}(\mathrm{kg})$ & body mass \\
\hline $\operatorname{MR}\left(1 \mathrm{O}_{2} \min ^{-1}\right)$ & metabolic rate \\
\hline $\mathrm{MR}_{\mathrm{s}}\left(\mathrm{l} \mathrm{O}_{2} \min ^{-1}\right)$ & surface metabolic rate \\
\hline${ }_{\mathrm{c}} \mathrm{MR}_{\mathrm{s}}\left(\mathrm{l} \mathrm{O}_{2} \min ^{-1}\right)$ & $\begin{array}{l}\text { mass-corrected surface } \\
\text { metabolic rate }\end{array}$ \\
\hline $\operatorname{RMR}\left(1 \mathrm{O}_{2} \min ^{-1}\right)$ & resting metabolic rate \\
\hline$\dot{V}_{\mathrm{O}_{2}}\left(\mathrm{l} \mathrm{O}_{2} \min ^{-1}\right)$ & rate of $\mathrm{O}_{2}$ consumption \\
\hline
\end{tabular}


saved to a laptop. Temperature $\left({ }^{\circ} \mathrm{C}\right)$ and humidity $(\%)$ of the excurrent gas were measured using a commercial sensor (Springfield Precise Temp. Springfield Precision Instrument). Measurement of humidity of the excurrent air made it possible to correct flow to STP dry (STPD). The effective volume of the system, including the volume of the respirometer and the plastic hose connected to the analyzer was $120 \mathrm{l}$. A flow rate of $4751 \mathrm{~min}^{-1}$ gave a time constant of $15 \mathrm{~s}$ and the time required to reach a $95 \%$ fractional transformation to a new steady state was $3.2 \times$ the time constant or $48 \mathrm{~s}$ (Fahlman et al. 2005).

The $\mathrm{O}_{2}$ and $\mathrm{CO}_{2}$ analyzers were calibrated before and after each trial using ambient air $\left(20.94 \% \mathrm{O}_{2}\right.$, $\sim 0.05 \% \mathrm{CO}_{2}$ ) and a commercial mixture of $1.0 \% \mathrm{CO}_{2}$ in $\mathrm{N}_{2}$ (Praxair). Simultaneous $\mathrm{N}_{2}$ and $\mathrm{CO}_{2}$ dilution tests (Fahlman et al. 2005) were used to determine the accuracy of the respirometry system. These tests were repeated regularly between trials and showed that the difference between the observed and expected values were within $4 \%$. Addition of $\mathrm{CO}_{2}$ confirmed that negligible amounts of $\mathrm{CO}_{2}$ were lost by dissolving in the seawater.

A PVC tube was extended to depth and attached to a pump system located on the corner of the barge (bilge pump [Rule] submerged, 14 to $400 \mathrm{l} \mathrm{h}^{-1}$ ) and a bladex valve with a plunger. The tube and pump system allowed fish (previously frozen herring, cut into $\sim 25 \mathrm{~g}$ pieces) to be delivered to a predetermined depth at a constant rate of 10 fish pieces $\mathrm{min}^{-1}$. Two underwater cameras, 1 at the bottom of the cage (surface camera [650 Sea-Drop, Sea-Viewer Underwater Video System]) and the other at the end of the feeding tube (depth camera [Scout XL, AquaVu Underwater Viewing System]), were connected to a monitor (AquaVu Underwater Viewing System, Scout XL), making it possible to observe the sea lion at depth and when inside the dome. The output from the cameras was fed to a DVD recorder allowing each dive trial to be recorded.

Water temperatures at the surface and at the end of the feeding tube were monitored during each trial using remote temperature loggers (Onset Computer Corp.). Temperature at depth was $10.5 \pm 2.0^{\circ} \mathrm{C}$ in summer and $10.8 \pm 0.6^{\circ} \mathrm{C}$ in winter, and at the surface 14.4 $\pm 2.6^{\circ} \mathrm{C}$ in the summer and $10.0 \pm 1.5^{\circ} \mathrm{C}$ in the winter.

Trial procedure. Each sea lion was instructed by a trainer to swim into the dome. The trial started once the animal surfaced inside the dome. The animal was kept in the dome for approximately 6 min to measure the surface metabolic rate $\left(\mathrm{MR}_{\mathrm{s}}\right)$, but the time was extended if steady values of $\mathrm{O}_{2}$ and $\mathrm{CO}_{2}$ were not recorded during the last $2 \mathrm{~min}$. Previous unpublished trials at our facility of resting metabolism measured up to 30 min have shown that this shorter duration is sufficient to accurately measure the surface metabolic rate and short enough to avoid stress. Following the measurement of $\mathrm{MR}_{\mathrm{s}}$, the animal was instructed to dive to a pre-determined depth $(10,30$, or $50 \mathrm{~m})$ where pieces of herring were delivered until the sea lion decided to return to the dome. While submerged, the animal did not receive any instructions from the trainer and the duration of the dive was determined by the sea lion. After re-surfacing, the sea lion was kept in the dome via behavioural control until the $\dot{V}_{\mathrm{O}_{2}}$ had returned to pre-dive levels (approx. 5-7 min). Each trial included 3-6 repeated dives $\left(1\right.$ trial d $\left.^{-1}\right)$ for each animal. Dives shorter than $20 \mathrm{~s}$ and those where the sea lion accidentally surfaced outside the dome were excluded from the analyses.

Definitions and calculation of $\mathbf{M R}_{\mathrm{s}}$ and DMR. Activity level varied when the sea lions were breathing in the respirometry dome within the cage. The animals did not always remain resting at the water surface but alternated resting periods at the surface with periods lying at the bottom of the cage. Hence, the obtained metabolic values during prolonged periods in the respiratory dome were defined as $\mathrm{MR}_{\mathrm{s}}$ rather than as resting metabolic rate. $\dot{V}_{\mathrm{O}_{2}}$ was calculated by integrating the instantaneous $\mathrm{O}_{2}$ consumption rate (Bartholomew et al. 1981) over periods when the sea lion was breathing in the dome. $\mathrm{MR}_{\mathrm{s}}$ was computed as the total $\mathrm{O}_{2}$ consumed during a period of stable $\mathrm{O}_{2}$ values (usually between 2 to $3 \mathrm{~min}$ ) and divided by the duration of stable $\mathrm{O}_{2}$ values. DMR was estimated by dividing the total $\mathrm{O}_{2}$ consumed during the entire post-dive surface interval by the duration of the dive and post-dive surface interval (Sparling \& Fedak 2004). Consequently, this is not a true measure of diving metabolic rate, but rather an estimate of the cost of each dive event (Fahlman et al. 2008c).

As metabolic rate is related to $M_{\mathrm{b}}$ with massexponent estimates ranging between 0.66 to 0.75 , depending on whether one subscribes to the geometric or quarter-power scaling exponent (West et al. 2002, White 2003), fasting-induced hypometabolism would be detected as a deviation away from this universal constant (Fahlman et al. 2005). Therefore, mass-corrected DMR ${ }_{\mathrm{c}} \mathrm{DMR}=\mathrm{DMR} \times \mathrm{M}_{\mathrm{b}}{ }^{-0.714} ; \mathrm{ml} \mathrm{O}_{2} \mathrm{~min}^{-1}$ $\left.\mathrm{kg}^{-0.714}\right)$ and $\mathrm{MR}_{\mathrm{S}}\left({ }_{\mathrm{c}} \mathrm{MR}_{\mathrm{s}}=\mathrm{MR}_{\mathrm{s}} \mathrm{M}_{\mathrm{b}}^{-0.714}\right)$ were calculated using an intra-specific mass-exponent reported for marine mammals (Hunter 2005). Using this massexponent ensured that observed changes in DMR and $\mathrm{MR}_{\mathrm{s}}$ were independent of concurrent changes in $M_{\mathrm{b}}$.

Calculation of foraging duration $\left(\mathbf{d}_{\mathrm{f}}\right)$. The total decrease in foraging time was estimated by calculating the effect of the increase in ${ }_{c} \mathrm{DMR}$ on available foraging duration $\left(\mathrm{d}_{\mathrm{f}}\right.$, this excludes ascent and descent duration). The fractional change in ${ }_{c} \mathrm{DMR}\left(\Delta_{\mathrm{c}} \mathrm{DMR}, \%\right)$ during the recovery changed the total dive duration $\left(\mathrm{d}_{\mathrm{t}}\right)$ by:

$$
\Delta \mathrm{d}_{\mathrm{t}}=\Delta_{\mathrm{c}} \mathrm{DMR} \times \mathrm{d}_{\mathrm{t}}
$$


where $\Delta d_{t}$ is the change in total dive duration (min). In the present, the mean dive duration for a dive to $50 \mathrm{~m}$ was $3.7 \mathrm{~min}$ with an available foraging time of $1.2 \mathrm{~min}$ (Fahlman et al. 2008a). The change in available foraging time $\left(\Delta \mathrm{d}_{\mathrm{f}}, \%\right)$ was thereafter estimated as

$$
\left(\Delta \mathrm{d}_{\mathrm{f}}=\Delta \mathrm{d}_{\mathrm{t}} \mathrm{d}_{\mathrm{f}}^{-1}\right)
$$

Statistical analysis. Our objective was to assess how mass-corrected surface and diving metabolic rate changed after fasting and over the recovery period. We did this by comparing ${ }_{\mathrm{C}} \mathrm{MR}_{\mathrm{S}}$ and ${ }_{\mathrm{C}} \mathrm{DMR}$ separately for the following: (1) the direct effect of fasting (Pre-fast vs. Post 1 metabolic rates), (2) the nature of recovery from a fast (Post 1 vs. Post 2, Post 3, Post 4 and Post 5), and (3) the overall effect of fasting, including the direct effect of fasting and the recovery period (Pre-fast to Post 5 metabolic rates).

Statistical analyses were performed using the software RGui (R: A Language and Environment for Statistical Computing, R Foundation for Statistical Computing, v.2.5.1, 2007). The effect of fasting on ${ }_{\mathrm{C}} \mathrm{MR}_{\mathrm{s}, \mathrm{C}} \mathrm{DMR}$ and $M_{\mathrm{b}}$ (dependent variables) was determined using linear mixed-effects (lme) models (nlme library from Pinheiro et al. 2006). Fasting session (Fast 1, 2 or 3), fasting state (Pre-fast to Post 5), dive duration, dive number (the number of the dive during the diving trial) and dive depth were tested as independent fixed covariates. Animal was included as a random effect. This approach considered individual variation relative to the population mean by accounting for the correlation between repeated measurements on the same animal. Forward and backward stepwise techniques were used to search for the best model. Selection of the model best explaining the data was based on Akaike Information Criterion (AIC).

Statistical significance for each variable in the mixed effect model was set at $\alpha \leq 0.05$. In this study $p$-values $\leq 0.05$ were considered as significant whereas $0.05<\mathrm{p}$ $\leq 0.1$ were considered a trend. Data are presented as mean values $\pm \mathrm{SD}$ unless otherwise stated.

\section{RESULTS}

\section{Effects of fasting on body mass and food intake}

Mean $M_{\mathrm{b}}$ before the fast was similar between the 3 fasting sessions, and was 144.2 $\pm 0.7,219.6 \pm 0.4$ and $168.5 \pm 1.6 \mathrm{~kg}$ respectively for F00BO, F97SI and F97HA ( $p>0.1$ ). Details of changes in $M_{\mathrm{b}}$ during the fasting and recovery periods are summarized in Table 4 .

Total $M_{\mathrm{b}}$ loss was higher in the winter compared with the summer $(\mathrm{p}=0.044)$. The daily $M_{\mathrm{b}}$ loss $(\%)$ decreased linearly in relation to pre-fast values during the fast $(p<0.01)$ and the decrease was significantly
Table 4. Eumetopias jubatus. Body mass $M_{\mathrm{b}}(\mathrm{kg})$ and change in $M_{\mathrm{b}}$ (kg and \%) during a 9 to $10 \mathrm{~d}$ fasting and a 2 to $14 \mathrm{~d}$ recovery period for 3 female Steller sea lions in summer and winter

\begin{tabular}{|lcc|}
\hline & Summer & Winter \\
\hline$M_{\mathrm{b}}$ before fast (kg) & $177.5 \pm 38.7$ & $177.3 \pm 37.8$ \\
$M_{\mathrm{b}}$ after fast $(\mathrm{kg})$ & $161.4 \pm 36.1$ & $158.7 \pm 34.8$ \\
Total $M_{\mathrm{b}}$ loss during fast (\%) & $-9.5 \pm 0.3$ & $-10.6 \pm 0.8$ \\
$M_{\mathrm{b}}$ loss $\mathrm{d}^{-1}$ during fast (\%) & $-1.06 \pm 0.10$ & $-1.24 \pm 0.12$ \\
Total gain in $M_{\mathrm{b}}$ during & $6.5 \pm 1.2$ & $6.3 \pm 1.2$ \\
recovery $(\%)$ & & \\
Gain in $M_{\mathrm{b}} \mathrm{d}^{-1}$ during & $0.54 \pm 0.10$ & $0.50 \pm 0.11$ \\
recovery $(\%)$ & & \\
\hline
\end{tabular}

higher in the winter ( $p=0.016)$ compared with the summer. The average daily gain in $M_{\mathrm{b}}$ during the $14 \mathrm{~d}$ recovery period was $0.52 \pm 0.03 \% \mathrm{~d}^{-1}$ and did not differ between seasons ( $p>0.1$; Fig. 1A).

The daily mass-specific rate of loss in $M_{\mathrm{b}}\left(\mathrm{g} \mathrm{kg}^{-1} \mathrm{~d}^{-1}\right)$ remained steady throughout the fasting period ( $\mathrm{p}>$ 0.1 ) and was higher during the winter fast (13.4 $\mathrm{g} \mathrm{kg}^{-1}$ $\mathrm{d}^{-1}$ ) compared with the summer fast $\left(11.0 \mathrm{~g} \mathrm{~kg}^{-1} \mathrm{~d}^{-1}\right.$; $\mathrm{p}=0.039$; Fig. 1B). The daily mass-specific rate of gain in $M_{\mathrm{b}}$ during recovery was similar between seasons ( $p>0.1$ ), but decreased asymptotically toward zero with days of recovery.

\section{Effect of fasting on metabolic rate}

There was a significant correlation between $\log _{10^{-}}$ transformed surface metabolic rate $\left(\log \mathrm{MR}_{\mathrm{s}}\right)$ and body mass $\left(\log M_{\mathrm{b}}, \mathrm{p}<0.01\right)$. For pre-fast $\log \mathrm{MR}_{\mathrm{s}}$ the massexponent was 1.44, while the exponent for the entire fasting session (Pre-fast to Post 5) was 1.12. A similar analysis for dive metabolic rate (DMR) gave a massexponent of 0.72 for the pre-fast value $(p<0.01)$, and 0.76 when including all values (Pre-fast to Post 5).

Surface metabolic rates (Pre-fast to Post 5) ranged between 0.71 to $2.09 \mathrm{l} \mathrm{O}_{2} \mathrm{~min}^{-1}$, and ${ }_{\mathrm{C}} \mathrm{MR}_{\mathrm{s}}$ ranged between 20 to $48 \mathrm{ml} \mathrm{O}_{2} \mathrm{~min}^{-1} \mathrm{~kg}^{-0.714}$. Mean ${ }_{\mathrm{C}} \mathrm{DMR}$ was $12.4 \pm 12.8 \%$ higher than ${ }_{\mathrm{C}} \mathrm{MR}_{\mathrm{s}}$ for the 3 fasting sessions (Pre-fast to Post 5; p < 0.05), but mass-corrected surface metabolic rate did not differ between the 2 summer fasts, Fast 1 and 2 ( $p>0.1$ ). The data were therefore pooled to compare the summer fast with the winter fast (Fast 3). Overall, ${ }_{\mathrm{c}} \mathrm{MR}_{\mathrm{s}}$ was significantly higher in the winter compared with the summer, both before and after fasting ( $p<0.031$ ). Mass-corrected surface metabolic rate decreased in both seasons on the last day of fasting (Post 1), and dropped more in the summer $(-16.4 \pm 4.7 \%, \mathrm{p}<0.0001)$ than winter $(-8.0 \pm$ $9.0 \%, \mathrm{p}<0.05)$. 

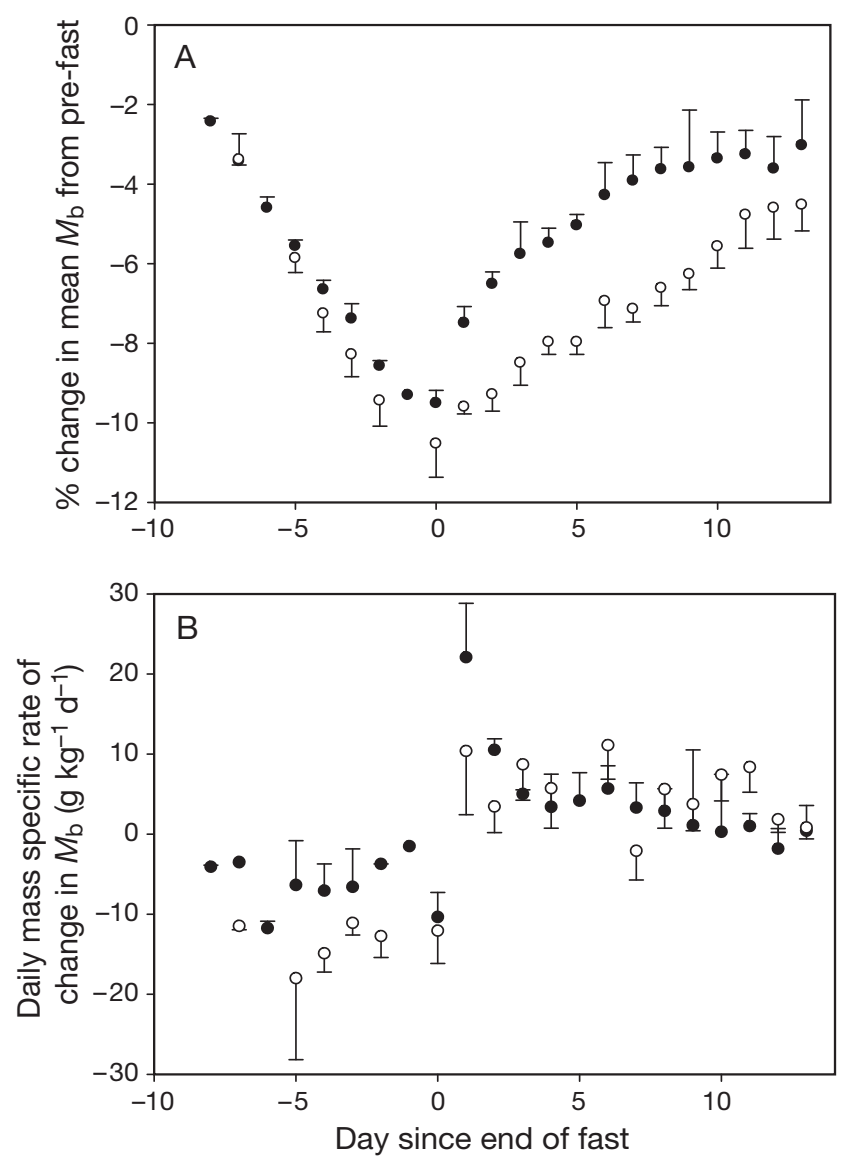

Fig. 1. Eumetopias jubatus. Change in mean body mass $( \pm \mathrm{SD})$ of 3 female Steller sea lions during fasting (Days -10 to -1 ) and subsequent feeding (Days 0 to 13): (A) percent change in $M_{\mathrm{b}}$ relative to pre-fasting mass during summer (closed circles) and winter (open circles); (B) daily rate of mass loss relative to the previous day mass $\left(\mathrm{g} \mathrm{kg}^{-1} \mathrm{~d}^{-1}\right)$ in summer (closed circles) and winter (open circles). Animals began receiving food on Day 0. Negative day-values = remaining number of fasting days Positive values $=$ number of recovery days since end of fasting

Independent of season, ${ }_{\mathrm{c}} \mathrm{MR}_{\mathrm{s}}$ was similar to pre-fast values on the second day of recovery, where it stabilized and remained throughout the recovery period (Fig. 2). An asymptotically increasing function showed that the intercept ( $p=0.0001$, Eqs. (3) \& (4) but not the slope $(p>0.1)$ differed between seasons during the $14 \mathrm{~d}$ recovery period. The best equations to describe mass-corrected metabolic rate $\left(\mathrm{ml} \mathrm{O} \mathrm{Om}^{-1} \mathrm{~kg}^{-0.714}\right)$ relative to days post-fast were:

$$
\begin{aligned}
& { }_{\mathrm{c}} \mathrm{MR}_{\mathrm{s} \text { summer }}=2.57 \cdot 10^{-2}+9.0 \cdot 10^{-3} \cdot\left(1-\mathrm{e}^{-\mathrm{d}}\right) \\
& { }_{\mathrm{C}} \mathrm{MR}_{\mathrm{s} \text { winter }}=3.25 \cdot 10^{-2}+7.23 \cdot 10^{-3} \cdot\left(1-\mathrm{e}^{-\mathrm{d}}\right)
\end{aligned}
$$

Each dive trial consisted of 3 to 8 dives. Analysing the first post-fasting trial (Post 1) revealed that ${ }_{\mathrm{c}} \mathrm{MR}_{\mathrm{s}}$ increased significantly after the first dive in the trial ( $p<0.01)$, compared to pre-dive values, and remained elevated until the end of the trial. For the pre-fasting

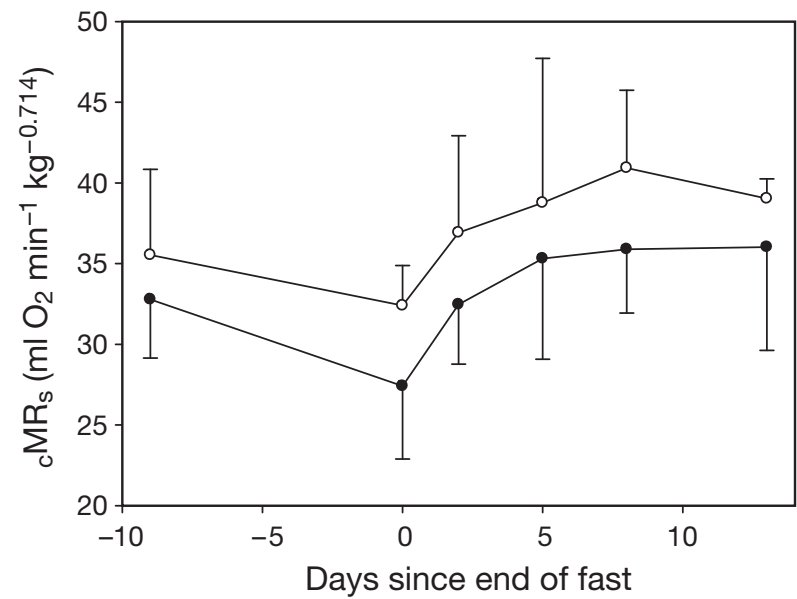

Fig. 2. Eumetopias jubatus. Mean $( \pm \mathrm{SD})$ mass-corrected surface metabolic rates $\left({ }_{c} \mathrm{MR}_{\mathrm{s}}\right.$ l $\left.\mathrm{l} \mathrm{O}_{2} \mathrm{~min}^{-1} \mathrm{~kg}^{-0.714}\right)$ for 3 female Steller sea lions prior to fasting (Day -9) and during the $14 \mathrm{~d}$ recovery period (Days 0 to 13) that followed the $9 \mathrm{~d}$ fast in summer (closed circles) and winter (open circles). Animals began receiving food on Day 0. Negative day-values = remaining number of fasting days; positive values = number of recovery days since end of fasting

trial and the remaining post-fasting trials (Post 2 to Post 5), ${ }_{c} \mathrm{MR}_{\mathrm{s}}$ remained constant throughout the trial and did not differ from the pre-dive value $(p>0.3)$. This was true for both the summer (Fig. 3A) and the winter fasts (Fig. 3B).

The overall mean dive duration was $3.4 \pm 1.5 \mathrm{~min}$ (range 0.4 to $7.0 \mathrm{~min}$ ). Dive duration increased with depth $(\mathrm{p}>0.0001)$ from $2.9 \pm 1.2 \mathrm{~min}$ at $10 \mathrm{~m}$ (summer Fast 2), to $3.7 \pm 1.6 \mathrm{~min}$ at $20 \mathrm{~m}$ to $50 \mathrm{~m}$ (summer, Fast 1 ), and $3.6 \pm 1.5 \mathrm{~min}$ at $30 \mathrm{~m}$ to $50 \mathrm{~m}$ during winter (Fast 3).

DMR ranged between 0.97 to $2.30 \mathrm{l} \mathrm{O}_{2} \mathrm{~min}^{-1}$ and ${ }_{\mathrm{C}} \mathrm{DMR}$ between 30 to $53 \mathrm{ml} \mathrm{O}_{2} \mathrm{~min}^{-1} \mathrm{~kg}^{-0.714}$. Neither dive depth, dive sequence number, nor dive duration significantly affected mass-corrected diving metabolic rate $(p>0.1)$. As ${ }_{c} D M R$ did not differ between the 2 summer fasts $(p>0.1)$, the data were pooled for the summer fasts and compared with the winter fast.

Mass-corrected diving metabolic rate differed between seasons and was significantly higher in the winter compared with the summer, both before and after the fast $(p<0.0001)$. Immediately following the fast (Post 1), cDMR increased in the winter (13.5 \pm $8.1 \%, \mathrm{p}<0.0001)$ but did not change in the summer $(-1.1 \pm 3.2 \% ; \mathrm{p}>0.05)$.

During the recovery period in both seasons, ${ }_{c} \mathrm{DMR}$ initially increased and then decreased towards the pre-fast value (Fig. 4). The shape of the recovery curve for mass-corrected diving metabolic rate was best described by a polynomial equation ( $p<0.05)$, and showed a significant difference in intercepts $(p<0.0001)$ and a trend towards a difference in shape of the re- 


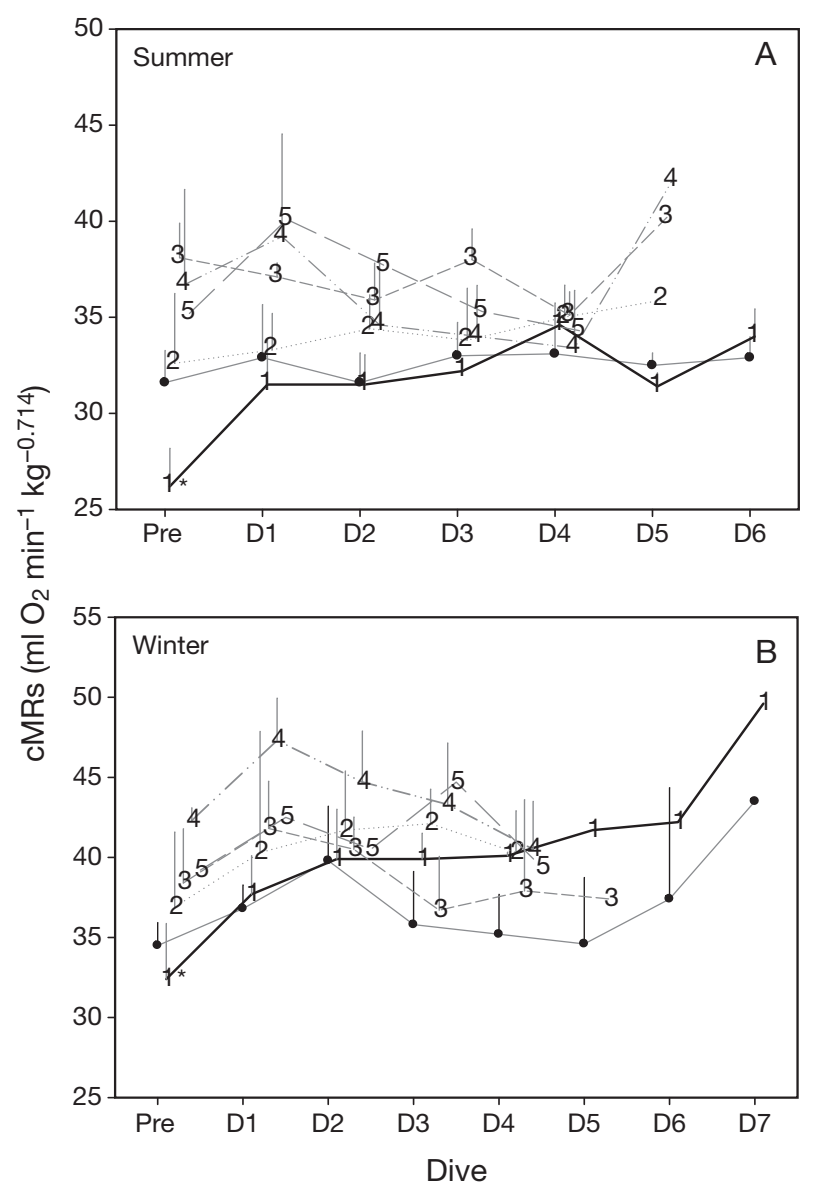

Fig. 3. Eumetopias jubatus. Mean $( \pm \mathrm{SD})$ mass-corrected surface metabolic rates $\left({ }_{\mathrm{C}} \mathrm{MR}_{\mathrm{s} i} 1 \mathrm{O}_{2} \mathrm{~min}^{-1} \mathrm{~kg}^{-0.714}\right)$ associated with individual dives made by 3 female Steller sea lions before $(\bullet)$ and following fasting (1-5) during (A) summer and (B) winter. The numeric symbols (1-5) indicate the pre-defined postfasting days when metabolism was measured following the fast. Metabolism was measured prior to diving (Pre) and following each of up to 7 consecutive dives (D1-D7). Stars show significant values in relation to the rest of the dives in the trial

covery curve between seasons $(p<0.1)$. The best equations to describe mass-corrected metabolic rate $\left(\mathrm{ml} \mathrm{O}_{2}\right.$ $\min ^{-1} \mathrm{~kg}^{-0.714}$ ) relative to days post-fast were:

${ }_{\mathrm{C}} \mathrm{DMR}_{\text {summer }}=3.63 \cdot 10^{-2}+8.81 \cdot 10^{-4} \cdot \mathrm{d}+-6.70 \cdot 10^{-5} \cdot \mathrm{d}^{2}(5)$

${ }_{\mathrm{C}} \mathrm{DMR}_{\text {winter }}=4.46 \cdot 10^{-2}-1.20 \cdot 10^{-4} \cdot \mathrm{d}+1.10 \cdot 10^{-5} \cdot \mathrm{d}^{2}(6)$

The total increase in ${ }_{\mathrm{C}} \mathrm{DMR}$ during the $14 \mathrm{~d}$ recovery period that followed fasting was predicted by integrating the predicted mass-corrected diving metabolic rate recovery curves (Eqs. 5 and 6), after correcting for seasonal differences (difference in pre-fast ${ }_{c} D M R$ in the summer and the winter fast). The increase in mass-corrected diving metabolic rate during the entire recovery period was $12 \%$ in the winter and $3 \%$ in the summer.

As transit time to and from the prey patch was not affected by fasting, the $12 \%$ post-fasting increase in

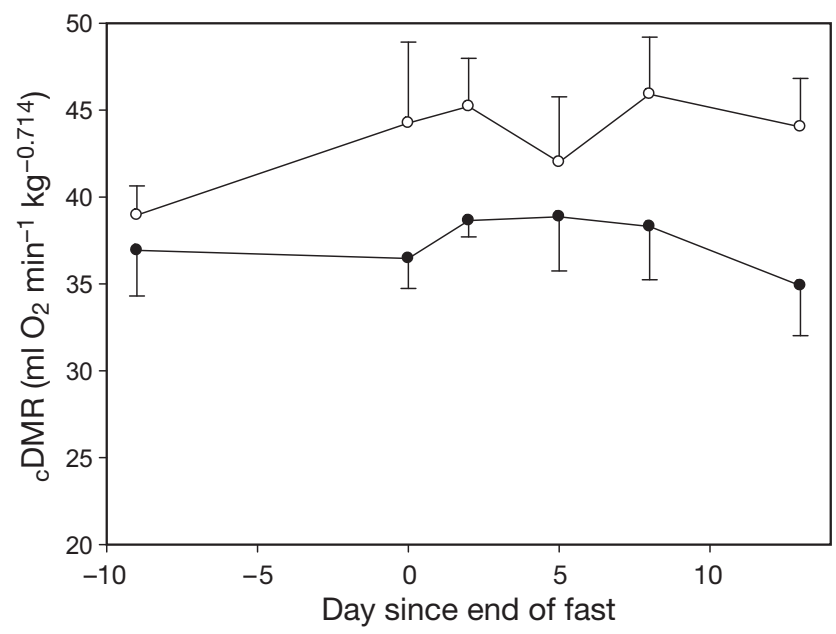

Fig. 4. Eumetopias jubatus. Mean $( \pm \mathrm{SD})$ mass-corrected dive metabolic rate ${ }_{\mathrm{c}} \mathrm{DMR}$; dive + surface interval; $\mathrm{l} \mathrm{O}_{2} \mathrm{~min}^{-1}$ $\mathrm{kg}^{-0.714}$ ) for 3 female Steller sea lions before and after a 9 to $10 \mathrm{~d}$ fast and during a $14 \mathrm{~d}$ recovery period in summer $(\bullet)$ and winter (O). Animals began receiving food on Day 0. Negative day-values = remaining number of fasting days; positive values $=$ number of recovery days since end of fasting

${ }_{\mathrm{C}} \mathrm{DMR}$ in winter and $3 \%$ increase in summer resulted in an estimated $18 \%$ decrease in foraging duration in the winter and $5 \%$ decrease in the summer during the $14 \mathrm{~d}$ recovery period.

\section{DISCUSSION}

Previous studies with sea lions indicated changes in energy demand during the breeding season (Williams et al. 2007, Jeanniard du Dot et al. 2008). Our data complement those results and also show that prolonged fasting affects the metabolic cost of foraging in a large, freely-diving marine mammal. Our data revealed that sea lions significantly decreased their ${ }_{\mathrm{C}} \mathrm{MR}_{\mathrm{s}}$ after fasting in summer $(-16.4 \%)$ and winter $(-8.0 \%)$, and indicates a fasting-induced metabolic depression that is beyond what can be attributable solely to normal allometric changes in $M_{\mathrm{b}}$. Fasting did not affect ${ }_{C} \mathrm{DMR}$ in the summer but caused a $13.5 \%$ increase in ${ }_{\mathrm{C}} \mathrm{DMR}$ during winter immediately following the fast.

One of the most striking results of our study is the divergent seasonal response in ${ }_{C} \mathrm{DMR}$ compared with the decrease in ${ }_{C} M R_{S}$ during both seasons. This divergent metabolic response can potentially be explained by an increase in thermoregulatory cost while diving after the fast. Such an increased heat loss is assumed to result from a decrease in the insulative fat stores which was particularly noticeable in the winter trial with greater weight loss. While ${ }_{\mathrm{C}} \mathrm{MR}_{\mathrm{S}}$ returned to pre-fast values on the second day of recovery, ${ }_{c} \mathrm{DMR}$ was elevated 
throughout the recovery period (while $M_{\mathrm{b}}$ was lower), supporting the suggestion that the sea lions experienced a fasting-induced thermoregulatory challenge while diving during the recovery period. In addition, our data also indicate that digestion was occurring while diving following the fast, as shown by an increase in mass-corrected surface metabolic rate while diving. As a result, calculated available foraging time decreased by $5 \%$ in the summer and as much as $18 \%$ in the winter during the recovery period. Such a decrease in foraging ability following fasting would make Steller sea lions more vulnerable to changes in prey availability during the recovery period, especially in the winter.

\section{Change in $M_{b}$ after fasting}

Body tissue is used as a nutritional resource when mammals fast. In our study, both total $M_{\mathrm{b}}$ loss and the daily $M_{\mathrm{b}}$ loss from pre-fast values after a 9 to $10 \mathrm{~d}$ fast was higher in the winter $\left(-10.6 \%\right.$ in total, $\left.-1.2 \% \mathrm{~d}^{-1}\right)$ compared with the summer $\left(-9.5 \%\right.$ in total, $\left.-1.1 \% \mathrm{~d}^{-1}\right)$ (Fig. 1). The daily percent $M_{\mathrm{b}}$ loss from pre-fast values was generally lower than what has been previously reported in fasted subadult $\left(-1.2 \% \mathrm{~d}^{-1} ; 3.5-6.0 \mathrm{yr}\right.$ old $)$ and juvenile $\left(-1.8 \% \mathrm{~d}^{-1} ; 1.8\right.$ to $2.5 \mathrm{yr}$ old $)$ Steller sea lions in either season $\left(-1.7 \% \mathrm{~d}^{-1}\right.$ and $\left.-1.5 \% \mathrm{~d}^{-1}\right)$ (Rea et al. 2007). The percent $M_{\mathrm{b}}$ loss in our study was also lower than that reported in fasted juveniles $\left(-1.53 \% \mathrm{~d}^{-1}\right.$, 2.5 to 4.5 yr old; Rosen \& Trites 2002). This lower rate of mass loss was surprising since, in contrast to previous studies, our animals were housed in a floating pen exposed to ambient environmental extremes.

While we did not believe our sea lions acquired any food during their fast, we cannot rule out the remote possibility that they captured small fish that might have swum into their pen. Although we never noted any small fish in the pen, we are cognisant that our experimental results may not be reflective of a true fast, and could instead indicate metabolic changes occurring during extreme food restriction.

A more likely explanation for the noted lower $M_{\mathrm{b}}$ loss is that our animals were older (6 to $9 \mathrm{yr}$ ) than the sea lions in the previous studies. Younger animals have a higher mass-specific metabolic rate (Kleiber 1975) and would therefore lose relatively more body mass. Previous studies have shown that juvenile Steller sea lions lost proportionally more weight compared to subadults during the breeding season (Rea et al. 2007), and that $M_{\mathrm{b}}$ loss during a short fast in a 6 -wk old pup was particularly high $\left(-2.5 \% \mathrm{~d}^{-1}\right)$ (Rea et al. 2000). In addition, younger individuals have additional metabolic priorities for growth and might not be able to depress their metabolic rate sufficiently to conserve body reserves during fasting.
A higher $M_{\mathrm{b}}$ loss in the winter compared with the summer concurs with previous acute food restriction studies among juvenile and subadult Steller sea lions (Kumagai et al. 2006) and fasted subadults (Rea et al. 2007). Subcutaneous fat is the preferred tissue catabolised during fasting, since it provides greater energy per mass than protein (Schmidt-Nielsen 1997) and this preference has been observed among Steller sea lions when fed restricted amounts of food (Kumagai et al. 2006, Jeanniard du Dot et al. 2008). The increase in energy utilisation in the winter could be due to lower environmental temperatures. The average temperature at the surface was higher in the summer compared with the winter, but there was only a slight difference in the temperature at depth between seasons. Nevertheless, the mean temperature during a diving bout (surface + dive) was lower in the winter (see 'Materials and methods: Experimental set up and variables measured'). In a homeotherm, temperatures below the lower limit of the thermoneutral zone (TNZ) increase energy requirements by increased thermoregulatory costs. We suggest that, in our study, water temperatures reached below the sea lions' TNZ in the winter. This resulted in an increase in thermoregulatory costs and greater rates of body mass loss in the winter compared with the summer.

\section{Change in metabolic rate after fasting}

Fasting has important consequences on specific physiological mechanisms such as digestion and thermoregulation. A reduction in metabolism by downregulation of body functions such as protein synthesis, thermoregulation, and digestion is a typical option for animals to limit energy expenditure and tissue catabolism in response to reduced energy intake (Øritsland 1990, Castellini \& Rea 1992, Guppy et al. 1994).

The sea lions in our study increased both ${ }_{\mathrm{C}} \mathrm{MR}_{\mathrm{s}}$ and ${ }_{\text {c }} \mathrm{DMR}$, before and after the fast, to compensate for the increased thermoregulatory challenge and higher $M_{\mathrm{b}}$ loss after the winter fast as compared with the summer fast. An increase in metabolic rate (in air) of Steller sea lions during periods of mass loss in winter was previously suggested to be evidence of a metabolic strategy that differed between winter and summer (Kumagai et al. 2006). However seasonal trends in metabolic strategies even under 'normal' feeding conditions diverge between species. While there is an overall trend in grey seals Halichoerus grypus, harbour seals Phoca vitulina, and harp seals Phoca groenlandica for seasonal decreases in resting metabolic rate (RMR) to be correlated with increases in $M_{\mathrm{b}}$ and body fat, the timing of these cycles differs between species (Hedd et al. 1997, Rosen \& Renouf 1998, Sparling et al. 2006). The 
pre-fast $M_{\mathrm{b}}$ in our study was similar between the summer and the winter fasts, suggesting similar levels of insulation. The higher MR in the winter likely reflects an increased thermoregulatory challenge associated with colder environmental conditions. The significantly higher food base in the winter during both the pre-fast and recovery period likely reflects changes in seasonal energy budgets, including these increased thermoregulatory costs, consistent with increased winter food requirements reported in other pinnipeds (Renouf and Noseworthy 1991, Rosen \& Renouf 1998, Jeanniard du Dot et al. 2008) and from bioenergetic modelling (Winship et al. 2002).

A reduction in metabolism was observed in our study directly after fasting (Post 1), with a significant decrease in ${ }_{\mathrm{C}} \mathrm{MR}_{\mathrm{s}}$ by $16.4 \%$ in the summer and $8.0 \%$ in the winter. These are comparable to the absolute changes in metabolism following similar fasts in Steller sea lions (30\% decrease while resting in air; Rosen \& Trites 2002) and sub-adult harbour seals (Phoca vitulina; $20 \%$ reduction while resting in water; Markussen \& Ryg 1992). Consequently our data support the suggestion that Steller sea lions respond to fasting by reducing energy requirements and consequently reducing surface metabolic rate, to save energy stores.

In contrast to ${ }_{\mathrm{C}} \mathrm{MR}_{\mathrm{s}}$, the ${ }_{\mathrm{C}} \mathrm{DMR}$ did not change in the summer and increased by $13.5 \%$ in the winter immediately after fasting (Post 1). This indicates that food restriction may result in additional changes in metabolic costs and physiological trade-offs while diving, compared with resting. These changes have been poorly investigated in diving mammals and may significantly affect foraging efficiency. Food restriction might alter the metabolic cost of diving and foraging through (1) an increased emphasis on the onset of digestion while actively foraging, (2) decreasing buoyancy that alters the metabolic cost of descending or ascending to depth and (3) increasing thermoregulatory costs due to the decrease in insulative fat stores and subsequent increase in both heat conductivity and convection while diving.

Digestive processes increase the rate of $\mathrm{O}_{2}$ consumption (Kriss et al. 1934). Some marine mammals, such as phocid seals, appear to defer digestion until the end of a foraging bout to maximize dive efficiency by decreasing metabolic overhead (Crocker et al. 1997, Sparling et al. 2007). However, the trade-off between prey acquisition and digestion has received limited attention (Rosen et al. 2007), especially in marine mammals under energetic pressure. Our study showed that ${ }_{\mathrm{C}} \mathrm{MR}_{\mathrm{S}}$ increased after the pre-dive period immediately after fasting (Post 1). This increase may indicate that sea lions begin to digest their food during foraging after a period of fasting, as opposed to their normal strategy of deferring digestion. This immediate onset of digestion after a period of diving was observed in both seasons, but not during the pre-fast trials or during any other recovery trial. An instantaneous onset of digestion after fasting implies that access to ingested energy is of higher priority than aerobic diving capacity. Immediate digestion may also indirectly decrease thermoregulatory costs of diving (Wilson and Culik 1991), although such thermal substitution is questionable in marine mammals (Rosen \& Trites 2003). Alternatively, the increase in mass-corrected surface metabolic rate after the pre-dive period might reflect cessation of metabolic depression upon exercise. However, this seems unlikely in our case since we compared periods of resting with periods of activity.

Alternately, changes in diving costs could have been due to changes in buoyancy via changes in body lipid content. Most buoyancy studies of marine mammals have focused on buoyancy related changes in dive behaviour (Webb et al. 1998, Skrovan et al. 1999, Sato et al. 2003, Watanabe et al. 2006), while few studies have investigated how changes in buoyancy affect the metabolic cost of diving (Fahlman et al. 2008b). One study investigating the effect of artificial changes in buoyancy on Steller sea lions (equivalent to $\sim 12$ to $26 \%$ subcutaneous fat) did not reveal any changes in DMR with changes in buoyancy for dives between 10 and $30 \mathrm{~m}$ (Fahlman et al. 2008b). Assuming that the fraction of subcutaneous fat to total body mass lost is similar to that previously measured in sea lions (winter 90 to $100 \%$, summer 65 to $73 \%$, Jeanniard du Dot et al. 2008), the amount of subcutaneous fat lost by sea lions in our study was similar to that found by Fahlman et al. (2008b). This suggests that the changes we observed were not caused by changes in buoyancy, perhaps because the experimental dive depths were too shallow to reveal any metabolic changes caused by alteration in buoyancy (Fahlman et al. 2008b). On the other hand, it is possible that the Steller sea adjusted to changes in buoyancy by adjusting their inhaled air volume to counteract changes in buoyancy as suggested by Kooyman (1973) and similar to what has been seen in king penguins (Sato et al. 2002). Hence, fasting induced changes in diving metabolic rate are not likely to be caused by the effect of changes in body lipid stores on cost of swimming via changes in buoyancy.

It is more likely that fasting-induced changes in diving metabolic rate were caused by changes in thermal capacity. Water conducts heat 26 times better than air and the convective heat loss can be 1000 times greater. Although no clear information exists on the thermoneutral zone (TNZ) for Steller sea lions, studies on adult California sea lion Zalophus californianus and Antarctic fur seal Arctocephalus gazella pups and yearlings suggest their lower critical temperature is approx $14^{\circ} \mathrm{C}$ (Liao 1990, Rutishauser et al. 2004). Rosen \& Trites (2003) estimated temperatures between 2 and 
$8^{\circ} \mathrm{C}$ to be partly below the TNZ of juvenile Steller sea lions. However, as body condition shows seasonal variation in many species of marine mammal the thermoneutral zone may also vary seasonally.

Steller sea lions and other otariids have a thin layer of insulative fat compared with phocids, and show less dramatic seasonal variation in total body lipid composition (e.g Webb et al. 1998, Pitcher \& Calkins 2000). However, catabolism of lipids for energy utilization will decrease the thickness of the hypodermal blubber layer. A theoretical model by Roscow (2001) has shown that the degree of heat loss in Steller sea lions under a variety of aquatic and terrestrial conditions increased when the insulative lipid layer decreased, resulting in a thermoregulatory challenge that increased the metabolic rate.

In our study, ${ }_{\mathrm{c}} \mathrm{MR}_{\mathrm{s}}$ decreased significantly immediately after fasting in both seasons, but decreased more in the summer $(-16.4 \%)$ compared with the winter $(-8.0 \%)$. This indicates one of 2 possible responses: (1) metabolic depression was greater than the increased heat loss caused by the reduction in body fat, or (2) the peripheral temperature was reduced to minimize thermoregulatory cost similarly to that seen in fasted king penguins (Fahlman et al. 2005). It was suggested that an animal that employs peripheral vasoconstriction can decrease the proportion of the body maintained at deep body temperature in response to changes in environment or insulation, hence reduce metabolic expenditure (see Worthy 1991). Unfortunately, we cannot determine which or to what extent these strategies were used by the sea lions because we were unable to measure core and peripheral body temperatures during our study.

The ratio between ${ }_{\mathrm{C}} \mathrm{DMR}$ and ${ }_{\mathrm{C}} \mathrm{MR}_{\mathrm{s}}$ increased after the fast in both seasons. Consequently, reduced insulation likely increased convective heat loss during active swimming, increasing the overall cost of foraging. During winter, this thermal challenge after the fast was great enough to increase mass-corrected diving metabolic rate above the pre-fasting value. If the sea lions had used a strategy of reduced body temperature to reduce mass-corrected surface metabolic rate, it is possible that the additional thermal challenge from swimming reached a lower critical threshold. Once this threshold was reached, further reduction in body temperature may not have been possible. The sea lions may therefore have been forced to increase heat production, resulting in a ${ }_{\mathrm{C}} \mathrm{DMR}$ that was higher than the pre-fast value, despite a reduction in the resting $M R_{s}$.

\section{Recovery period}

Independent of season, the decrease in ${ }_{\mathrm{c}} \mathrm{MR}_{\mathrm{s}}$ measured directly after the fast returned to pre-fast values within the second day of recovery, where it stabilised and remained throughout the recovery period (see Eqs. 3 and 4). ${ }_{\text {C }}$ DMR showed a similar increase but increased to values that exceeded the pre-fast trials, in both summer and winter (see Eqs. 5 and 6). The increase in ${ }_{\mathrm{C}} \mathrm{MR}_{\mathrm{s}}$ and ${ }_{\mathrm{C}} \mathrm{DMR}$ was most likely due to the up-regulation of body functions that were downregulated during the fast. Similar rapid recoveries of RMR have been seen in fasted harp seal pups, grey seal pups (Worthy 1987) and Steller sea lions (Rosen \& Trites 2002); although one study showed metabolic depression persisting at least one week after refeeding in harbour seals (Markussen \& Ryg 1992).

While resumption of normal body functions is rapid and may return mass-corrected surface metabolic rate to pre-fasting levels soon after re-feeding (Fahlman et al. 2005), mass-corrected diving metabolic rate during the recovery period remained elevated in the summer and to a higher degree in the winter. If a reduction in insulative body fat was partly responsible for the changes in foraging cost, DMR should have remained elevated during most of the recovery period while the sea lions were still restoring their fat reserves. This additional metabolic cost was particularly noticeable in the winter when fasting increased foraging cost by $12 \%$ during the $14 \mathrm{~d}$ recovery period compared to $3 \%$ in the summer. The elevated metabolic cost resulted in less $\mathrm{O}_{2}$ available for diving and foraging, thereby reducing the foraging efficiency. This increase in metabolic cost may seem small, but can have a significant overall effect on foraging behaviour by decreasing the foraging duration by as much as $18 \%$ in the winter and by $5 \%$ in the summer, during a 3.7 min dive to $50 \mathrm{~m}$. Available foraging time will further decrease with increasing dive depth (increased travel duration) or a decrease in swim speed. In addition, the higher metabolic rate also results in an increase in the total food requirement.

The particular vulnerability of Steller sea lions to food shortages in the winter agrees with the conclusions from other acute food restriction studies on Steller sea lions (Kumagai et al. 2006). In our study, the effect of fasting was also noticeable in the summer, the breeding season for this species. The foraging success of female Steller sea lions directly after the first week they spend on shore with their pups (the perinatal period) (Milette \& Trites 2003) and the subsequent foraging cycles are critical for the survival of the pup. A $5 \%$ increase in foraging cost during that time could therefore have a considerable effect on the health of both the mother and her pup and their subsequent chance of survival. This increase in foraging cost would further be enhanced by diminishing prey and changes in food quality and diversity. Inadequate food intake resulting in nutritionally stressed animals 
(Calkins et al. 1998) is one of the leading hypotheses to explain the drastic decline of the Western population of Steller sea lions in the Gulf of Alaska and Aleutian Islands (Trites \& Donnelly 2003, Guénette et al. 2006).

In conclusion, we suggest that reduced subcutaneous fat associated with fasting caused ${ }_{\mathrm{c}} \mathrm{DMR}$ of Steller sea lions to increase during winter and throughout a $14 \mathrm{~d}$ recovery period in winter and summer. This increase potentially decreased the sea lions' aerobic dive duration and foraging time, and occurred in spite of a drop in ${ }_{C} \mathrm{MR}_{\mathrm{s}}$. The increased ratio between the ${ }_{\mathrm{C}} \mathrm{DMR}$ and ${ }_{\mathrm{C}} \mathrm{MR}_{\mathrm{S}}$ of fasted sea lions further suggests that convective heat loss during active swimming may pose an additional metabolic challenge in both seasons. Additional costs may also be incurred by fasted animals initiating digestion while diving rather than postponing digestion until foraging has ceased. These findings can be incorporated into bioenergetic models to estimate the food requirements of Steller sea lions and better evaluate the impact that seasonal changes in the availability of prey can have on their populations.

Acknowledgements. Funding was provided to the North Pacific Universities Marine Mammal Research Consortium by the North Pacific Marine Science Foundation and the US National Oceanic and Atmospheric Administration. We especially thank the technical and administrative staff, and the trainers at the UBC Open Water Research Lab and the Vancouver Aquarium.

\section{LITERATURE CITED}

Bartholomew GA, Vleck D, Vleck C (1981) Instantaneous measurements of oxygen consumption during pre-flight warm-up and post-flight cooling in sphingid and saturniid moths. J Exp Biol 90:17-32

Calkins DG, Becker EF, Pitcher KW (1998) Reduced body size of Steller sea lions from a declining population in the Gulf of Alaska. Mar Mamm Sci 14:232-244

Castellini MA, Rea LD (1992) The biochemistry of natural fasting and its limits. Cell Mol Life Sci 48:575-582

Costa DP, Sinervo B (2004) Field physiology: physiological insights from animals in nature. Annu Rev Physiol 66: 209-238

Crocker DE, LeBoeuf BJ, Costa DP (1997) Drift diving in female northern elephant seals: implications for food processing. Can J Phys 75:27-39

Fahlman A, Schmidt A, Handrich Y, Woakes AJ, Butler PJ (2005) Metabolism and thermoregulation during fasting in king penguins Aptenodytes patagonicus, in air and water. Am J Physiol Regul Integr Comp Physiol 289:R670-R679

Fahlman A, Wilson R, Svärd C, Rosen DAS, Trites AW (2008a) Activity and diving metabolism correlate in Steller sea lions Eumetopias jubatus. Aquat Biol 2:75-84

Fahlman A, Hastie GD, Rosen DAS, Naito Y, Trites AW (2008b) The influence of buoyancy on diving metabolic rate of Steller sea lions Eumetopias jubatus. Aquat Biol 3:147-154

Fahlman A, Svärd C, Rosen DAS, Jones DR, Trites AW (2008c) Metabolic costs of foraging and the management of $\mathrm{O}_{2}$ and $\mathrm{CO}_{2}$ stores in Steller sea lions. J Exp Biol 211: 3573-3580

Guénette S, Heymans SJJ, Christensen V, Trites AW (2006) Ecosystem models show combined effect of fishing, predation, competition, and ocean productivity on Steller sea lions (Eumetopias jubatus). Can J Fish Aquat Sci 63: 2495-2517

Guppy M, Withers P (1999) Metabolic depression in animals: physiological perspectives and biochemical generalizations. Biol Rev Camb Philos Soc 74:1-40

Guppy M, Fuery CJ, Flanigan JE (1994) Biochemical principle of metabolic depression. Comp Biochem Physiol B $12: 230-238$

> Hedd A, Gales R, Renouf D (1997) Inter-annual consistency in the fluctuating energy requirement of captive harp seals. Polar Biol 18:311-318

Hunter AMJ (2005) A multiple regression model for predicting the energy requirement of marine mammals. MS thesis, University of British Columbia, Vancouver, BC

Jeanniard du Dot T, Rosen DAS, Trites AW (2008) Steller sea lions show diet dependent changes in body composition during nutritional stress and recover more easily from mass loss in winter than in summer. J Exp Mar Biol Ecol 367:1-10

Kleiber M (1975) The fire of life: an introduction to animal energetics. Robert E. Krieger Publication Company, New York

Kooyman GL (1973) Respiratory adaptations in marine mammals. Am Zool 13:457-468

> Kooyman GL, Ponganis PJ (1998) The physiological basis of diving to depth: birds and mammals. Annu Rev Physiol 60:19-32

Kriss M, Forbes EB, Miller RC (1934) The specific dynamic effects of protein, fat and carbohydrates as determined with the albino rate at different planes of nutrition. J Exp Biol 8:509-534

Kumagai S, Rosen DAS, Trites AW (2006) Body mass and composition responses to short-term low energy intake are seasonally dependent in Steller sea lions (Eumetopias jubatus). Comp Biochem Physiol 179:589-598

Kvadsheim PH, Folkow LP, Schytte A (2005) Inhibition of shivering in hypothermic seals during diving. Am J Physiol Regul Integr Comp Physiol 289:326-332

Liao JA (1990) An investigation of the effect of water temperature on the metabolic rate of the California sea lion (Zalophus californianus). MS thesis, University of California, Santa Cruz, CA

Markussen NH, Ryg M (1992) Metabolic rate and body composition of harbour seals during starvation and re-feeding. Can J Zool 70:220-224

Milette LL, Trites AW (2003) Maternal attendance pattern of Steller sea lions (Eumetopias jubatus) from stable and declining populations in Alaska. Can J Zool 81:340-348

Øritsland NA (1990) Starvation survival and body composition in mammals with particular reference to Homo sapiens. Bull Math Biol 52:643-655

Pinheiro J, Bates D, DebRoy S, Sarkar D (2006) nlme: Linear and nonlinear mixed effects models. R Package v. 3.1-86 R Development Core Team, Vienna

Pitcher KW, Calkins DG (2000) Steller sea lion body condition indices. Mar Mamm Sci 16:427-436

Rea LD, Costa DP (1992) Changes in standard metabolism during long-term fasting in northern elephant seal pups (Mirounga angustirostris). Physiol Zool 65:97-111

> Rea LD, Rosen DAS, Trites AW (2000) Metabolic response to fasting in 6-week-old Steller sea lion pups (Eumetopias jubatus). Can J Zool 78:890-894

Rea LD, Rosen DAS, Trites AW (2007) Utilisation of stored 
energy reserves during fasting varies by age and season in Steller sea lions. Can J Zool 85:190-200

Renouf D, Noseworthy E (1991) Changes in food intake, mass, and accumulation in association with variation in thyroid hormone levels of harbour seals (Phoca vitulina). Can J Zool 69:2470-2479

Roscow E (2001) Thermoregulation in Steller sea lions: a modelling approach. MS thesis, Texas A\&M University, Texas

Rosen DAS, Renouf D (1998) Correlates to seasonal changes in metabolism in Atlantic harbour seals (Phoca vitulina concolor). Can J Zool 76:1520-1528

Rosen DAS, Trites AW (2002) Changes in metabolism in response to fasting and food restriction in the Steller sea lions (Eumetopias jubatus). Comp Biochem Physiol B 132: 389-399

Rosen DAS, Trites AW (2003) No evidence for bioenergetic interaction between digestion and thermoregulation in Steller sea lions Eumetopias jubatus. Physiol Biochem Zool 76:899-906

Rosen DAS, Winship AJ, Hoopes LA (2007) Thermal and digestive constraints to foraging behaviour in marine mammals. Philos Trans Ser B 362:2151-2168

Rutishauser M, Costa DP, Goeble ME, Williams TM (2004) Ecological implications of body composition and thermal capabilities in young Antarctic fur seals (Arctocephalus gazella). Physiol Biochem Zool 77:669-681

Sato K, Naito Y, Kato A, Niizuma Y and others (2002) Bouyancy and maximal diving in penguins: Do they control inhaling air volume? J Exp Biol 205:1189-1197

Sato K, Mitani Y, Cameron MF, Siniff DB, Naito Y (2003) Factors affecting stroking patterns and body angle in diving Weddell seals under natural conditions. J Exp Biol 206: 1461-1470

Schmidt-Nielsen K (1997) Animal physiology: adaptation and environment. Cambridge University Press, Cambridge

Skrovan RC, Williams TM, Berry PS, Moore PW, Davis RW (1999) The diving physiology of bottlenose dolphins (Tursiops truncatus) II. Biomechanics and changes in buoyancy at depth. J Exp Biol 202:2749-2761

Sparling CE, Fedak MA (2004) Metabolic rates of captive grey seals during voluntary diving. J Exp Biol 207: 1615-1624

Editorial responsibility: Brent Stewart,

San Diego, California, USA
Sparling CE, Speakman JR, Fedak MA (2006) Seasonal variation in the metabolic rate and body composition of female grey seals: Fat conservation prior to high-cost reproduction in a capital breeder? J Comp Physiol B 176:505-512

Sparling CE, Fedak MA, Thopson D (2007) Eat now, pay later? Evidence of deferred food-processing costs in diving seals. Biol Lett 3:94-98

Trites AW, Donnelly CP (2003) The decline of Steller sea lions Eumetopias jubatus in Alaska: a review of the nutritional stress hypothesis. Mammal Rev 33:3-28

- Watanabe Y, Baranov EA, Sato K, Naito Y, Miyazaki N (2006) Body density affects stroke patterns in Baikal seals. J Exp Biol 209:3269-3280

Webb PM, Crocker DE, Blackwell SB, Costa DP, Le Boeuf BJ (1998) Effects of buoyancy on the diving behaviour of northern elephant seals. J Exp Biol 201:2349-2358

West GB, Woodruff WH, Brown JH (2002) Allometric scaling of metabolic rate from molecules and mitochondria to cells and mammals. Proc Natl Acad Sci USA 99:2473-2478

White CR (2003) Allometric analysis beyond heterogenous regression slopes: use of the Johnson-Neyman technique in comparative biology. Physiol Biochem Zool 76:134-140

Williams TM, Davis RW, Fuiman LA, Francis J and others (2000) Sink or swim: Strategies for cost-efficient diving by marine mammals. Science 288:133-136

Williams TM, Rutishauser M, Long B, Fink T, Grafney J, Mostman-Liwanag H, Casper D (2007) Seasonal variability on otariid energetics: implications for the effects of predators on localized prey resources. Physiol Biochem Zool 80:433-443

Wilson RP, Culik MB (1991) The cost of a hot meal: facultative specific dynamic action may ensure temperature homeostasis in post-ingestive endotherms. Comp Biochem Physiol 100:151-154

Winship AJ, Trites AW, Rosen DAS (2002) A bioenergetic model for estimating the food requirements of Steller sea lions Eumetopias jubatus in Alaska, USA. Mar Ecol Prog Ser 229:291-312

- Worthy GAJ (1987) Metabolism and growth of young harp and grey seals. Can J Zool 65:1377-1382

> Worthy GAJ (1991) Insulation and thermal balance in harp and grey seal pups. Comp Biochem Physiol A 100:845-852

Submitted: October 1, 2008; Accepted: November 23, 2009 Proofs received from author(s): December 23, 2009 